\title{
Mechanistic investigation of food effect on disintegration and dissolution of BCS class III compound solid formulations: the importance of viscosity
}

\author{
Asma Radwan ${ }^{\mathrm{a}}$, Gordon L. Amidon ${ }^{\mathrm{b}}$, and Peter Langguth ${ }^{\mathrm{a}, *}$ \\ anstitute of Pharmacy and Biochemistry, Johannes Gutenberg University, Mainz, Germany \\ ${ }^{\mathrm{b}}$ College of Pharmacy, The University of Michigan, Ann Arbor, MI 48109-1065, USA
}

\begin{abstract}
A negative food effect, i.e. a decrease in bioavailability upon the co-administration of compounds together with food, has been attributed particularly with high solubility/low permeability compounds (BCS class III). Different mechanisms have been proposed including intestinal dilution leading to a lower concentration gradient across the intestinal wall as well as binding of the active pharmaceutical ingredient to food components in the intestine and thereby decreasing the fraction of the dose available for absorption. These mechanisms refer primarily to the compound and not to the dosage form. An increase in viscosity of the dissolution fluid will in particular affect the absorption of BCS type III compounds with preferential absorption in the upper small intestine if the API release is delayed from the dosage form. The present study demonstrated that the increase in viscosity of the dissolution medium, following ingestion of a solid meal, may drastically reduce disintegration and dissolution. For that purpose the viscosity of the standard FDA meal was determined and simulated by solutions of HPMC in buffer. As model formulations, three commercially available tablets containing trospium chloride, a BCS class III $m$-cholinoreceptor antagonist was used. Trospium chloride drug products have been described to undergo a negative food effect of more than $80 \%$ following ingestion with food. The tablets showed prolonged disintegration times and reduced dissolution rates in viscous media, which could be attributed to changes in the liquid penetration rates. The effect was particularly significant for film-coated tablets relative to uncoated dosage forms. The results show the necessity of considering media viscosity when designing in vitro models of drug release for BCS type III drug formulations. Copyright ( 2012 John Wiley \& Sons, Ltd.
\end{abstract}

Key words: tablet disintegration; food effect; bioavailability; tablet dissolution; viscosity

\section{Introduction}

Food viscosity is one of the physiological parameters that can affect oral drug absorption [1]. Most of the studies that addressed the influence of viscosity on drug absorption demonstrate a reciprocal relationship between drug absorption and gastric viscosity [1-4]. In particular, drug products with low bioavailability are addressed, for which

*Correspondence to: Institute of Pharmacy and Biochemistry, Johannes Gutenberg University, Mainz, Germany.

E-mail: langguth@uni-mainz.de reduced postprandial absorption may lead to treatment failure and reduced therapeutic efficacy [5].

Different theories have been proposed to explain the mechanisms behind this food viscosity effect: (i) an inhibition of gastric emptying and/or modification of intestinal transit time [6,7]; (ii) a slower diffusion of drug molecules in the viscous lumen towards the intestinal membrane [6]; (iii) a reduction in the disintegration rate of the drug formulation under viscous conditions [8-11]; (iv) a reduction in drug dissolution rate $[4,6,9]$.

Previous studies examining drug dissolution and disintegration under viscous conditions showed reduced dissolution and disintegration rates [12-15], 
e.g. a reduction in the intrinsic dissolution rate by reduced diffusivity of benzoic acid in solutions of uncharged polymers according to the StokesEinstein equation [12]. Eshra et al. explained the reduction in ketoprofen absorption in humans by a retarding effect of food on the dissolution and diffusion rates of the dissolved drug [4]. Khoury et al. reported reduced dissolution kinetics of hydrocortisone acetate in dilute polymeric HPMC solutions, which act as a diffusion barrier [16]. Yet, there are also data showing that tablet disintegration, for example in canine stomach in the fed state, can be influenced by a viscosity-independent mechanism, i.e. a formation of a film coat around the dosage form $[10,11]$. Anwar et al. state that the viscosity plays an important role in delayed tablet disintegration in milk [8]. Parojčić et al. have reported reduced disintegration and dissolution rates of paracetamol tablets in viscous solutions of HPMC K4M. This was attributed to the poorer wetting of the tablet surface and reduced hydrodynamic shear stress [9].

Ingestion of foodstuffs containing water soluble fibres has been demonstrated to elevate the luminal viscosity by several orders of magnitudes [17-20]. Digesta viscosity, assessed in vivo using Echo planar magnetic resonance imaging, was found to lie in the range of $300-4000 \mathrm{mPa} \cdot \mathrm{s}$. The viscosity of gastric aspirates from healthy volunteers was reported to range from 200-2000 $\mathrm{mPa} \cdot \mathrm{s}$ immediately after food ingestion [21]. The average intestinal content viscosity values of rats fed with an oat based meal was found to lie in the range of $199-370 \mathrm{mPa} \cdot \mathrm{s}$ [22]. Although ingestion of a high viscosity meal increases the apparent viscosity of the stomach contents, digesta viscosity is reduced by rapid gastric dilution and increased luminal motility. The intake of highly viscous meals has been associated with strong gastric secretions. The volume of gastric secretions produced within $80 \mathrm{~min}$ in response to locust bean gum meal ingestion has been evaluated to be in the range of $95-157 \mathrm{ml}$ $[21,23]$. Shear conditions within GI are another important factor affecting the luminal viscosity. However, little is known on the shear rate that exists in the GI tract and there is no single standardized method to measure it. The motility within the GI tract varies considerably with location and meal composition. This makes the interpretation and evaluation of gastric viscosity data difficult [20].
Likewise, not even the effect of gastric dilution on the viscosity of an FDA standard meal at different shear rates has been reported.

The Biopharmaceutics Classification System (BCS) may be used to predict the type of food effect to be expected for the different classes of drugs. For BCS Class III drugs (high solubility, low permeability), a negative food effect is most likely to occur [24]. For example, trospium chloride, which belongs to this group, has a systemic availability of approximately $10 \%$ following oral administration. The first-pass effect is negligible since the compound has little affinity for CYP or phase II enzymes, thus poor permeability can be made responsible for its poor bioavailability [25]. Reduced bioavailability of trospium has been reported by the concomitant intake of a high fat meal, with an AUC value $86 \%$ lower than that obtained when it was administered in the fasted state [26].

A food effect is important to be considered in the early stages of drug development and in vitro dissolution methods may be helpful in this respect. Most of the in vitro models described in the Pharmacopeias, however, are not suitable for predicting the effect of food on drug release. Compendial media, such as simulated gastric fluid (SGF) and simulated intestinal fluid (SIF) are not representative of the GI environment in the fed state, particularly with respect to media viscosity. In an attempt to better predict the potential of food on drug absorption, various physiologically adapted media have been proposed. These systems consider factors related to media $\mathrm{pH}$ and compositions, such as bile salt, lipolytic enzymes and phospholipids contents. However, these media lack the physiological basis from a viscosity point of view [27]. Several media, such as milk and Ensure ${ }^{\circledR}$ Plus, have been proposed to simulate the postprandial gastric conditions [28]. However, the viscosity of these media may not reflect the change in the gastric viscosity after meal intake; therefore, they may not be suitable to predict viscosity-derived food effects. Only a few studies have so far addressed viscosity aspects in developing such media [29]. The effect of viscosity changes due to the dilutional process by gastric secretion has not been simulated. Yet, for better in vitro assessment of in vivo performance, it is essential to develop a dissolution medium that adequately reflects the postprandial viscous conditions in the GI tract. 
In this manuscript an in vitro model that is predictive for the viscosity effect following ingestion of a standard meal is proposed. The rheological behaviour of a homogenized standard meal recommended by FDA prior to and following dilution is characterized in order to design a representative viscosity-adjusted dissolution medium to simulate fed conditions.

Solutions containing different concentrations of VEAs were applied to understand the mechanism of drug release under viscous conditions; HPMC and guar gum polymeric solutions were selected to investigate the impact of the nature and structure of the VEA on the drug release process. The in vitro data are interpreted in light of the negative food effect encountered following the oral administration of solid dosage forms of a BCS III compound in vivo and gastrointestinal simulation technology is applied to establish in vitro/in vivo relationships.

\section{Materials and Methods}

\section{Materials and dosage forms}

Trospium chloride was obtained from Midas (Ingelheim, Germany), methyl hydroxypropyl cellulose E4M (Methocel E4M premium) from Synopharm (Germany). Guar gum, sodium hydroxide and potassium dihydrogen phosphate were purchased from Sigma Aldrich (Germany). Sodium acetate dihydrate was obtained from Carl Roth (Germany). Three commercially available trospium chloride tablet formulations were investigated: Spasmolyt ${ }^{\circledR}$, Spasmex $^{\circledR}$ and $\operatorname{Trospi}^{\circledR}$. Spasmolyt ${ }^{\circledR}$ and Spasmex ${ }^{\circledR}$ are film-coated tablets, whereas, Trospi ${ }^{\circledR}$ is a conventional tablet. Trospi ${ }^{\circledR}$ was kindly donated from Medac (Germany), Spasmex ${ }^{\circledR}$ was obtained from Dr R. Pfleger (Germany) and Spasmolyt ${ }^{\circledR}$ from Madaus (Germany).

\section{Media composition}

Various types of release media were used, differing in: (i) pH: $0.05 \mathrm{M}$ acetate buffer $\mathrm{pH} 4.6$ (USP), and simulated intestinal fluid (SIF) $\mathrm{pH} 6.8$ prepared from $6.8 \mathrm{~g} \mathrm{KH}_{2} \mathrm{PO}_{4}, 0.2 \mathrm{M} \mathrm{NaOH}$ and distilled water to $1000 \mathrm{ml}$. These media were used to simulate the fasted state under different $\mathrm{pH}$ (reference media); (ii) Viscosity: HPMC was added to SIF pH 6.8 and acetate buffer $\mathrm{pH} 4.6$ in different concentrations to represent the viscous fed state under various $\mathrm{pH}$ conditions. Table 1 lists the HPMC concentrations chosen to be used throughout the study. Guar gum was added to SIF in different proportions to provide information on the effect of the type of viscosity enhancing agent (VEA), e.g. its polymer structure on drug release process.

\section{Viscosity determination}

As a starting point for determining the suitable viscosity range for the different dissolution media to be used throughout this study and to design suitable media to simulate the viscous conditions in the fed state, the rheological profile of an FDA homogenized standard meal before and after dilution was characterized. The composition of this standard meal was: 2 slices of toast with butter, 2 eggs fried in butter, 2 strips of bacon, 4 ounces of hash brown potatoes, 8 ounces of whole milk [30]. Altered food viscosity through dilution by GI secretions was mimicked by diluting the homogenized standard meal with different volumes of water. The FDA diet $(460 \mathrm{ml})$, recommended to be co-administered with $240 \mathrm{ml}$ of water, was mixed thoroughly using a Waring blender and the initial viscosity of this homogenized food was determined. The diet was then diluted with $100 \mathrm{ml}$ of water and the viscosity was reanalysed. The dilution process was repeated once before the final viscosity was measured to yield a final volume of $900 \mathrm{ml}$.

To ascertain the concentrations of the different VEAs required for achieving viscosity similar to that of the homogenized meal and its dilutions, the rheological profiles of the different agents were constructed.

All viscosity measurements were performed in triplicate on a rotational rheometer RV 12 (HAAKE, Germany) using the MV DIN Sensor system at $37^{\circ} \mathrm{C}$. Viscosity values used for viscous

Table 1. Concentrations of different viscosity enhancing agents used in the study

\begin{tabular}{ll}
\hline Polymer $^{1}$ & \multicolumn{1}{c}{ Concentration of solution } \\
\hline HPMC E4M (pH4.6, 6.8) & $0.5 \%, 1 \%, 1.4 \%, 1.5 \%, 1.75 \%, 2 \%$ \\
Guar gum (pH 6.8) & $0.25 \%, 0.5 \%, 0.75 \%$ \\
\hline
\end{tabular}

${ }^{1}$ Concentration expressed as $\mathrm{w} / \mathrm{v}$.

Biopharm. Drug Dispos. 33: 403-416 (2012) DOI: $10.1002 /$ bdd 
media characterization in this study were determined at a shear rate of $1.29 \mathrm{~s}^{-1}$.

\section{Simulation of gastric viscosity in the fed state}

Matching the viscosity of the FDA homogenized meal can be designed by dissolving VEAs in SIF and acetate buffer and adjusting their rheological profiles to the standard meal. As the viscosity of the GI fluids is changing over time due to the dilution process, this process was simulated by the gradual addition of non-viscous dissolution media at different time intervals. The rate of dilution process was adjusted based on previous in vivo studies to $130 \mathrm{ml} / \mathrm{h} \mathrm{[21].}$

\section{Solubility determination}

Equilibrium solubility of trospium chloride in various media was determined at $37^{\circ} \mathrm{C}$. An excess amount of the drug was added to $3 \mathrm{ml}$ of the investigated media, which was kept in a shaker incubator maintained at $37^{\circ} \mathrm{C}$ for $24 \mathrm{~h}$. Thereafter, the solutions were filtered and assayed spectrophotometrically at $210 \mathrm{~nm}$. Solubility determinations were performed in duplicate.

\section{Density determination}

The density of the different solutions used was determined by weighing a $50 \mathrm{ml}$ pycnometer before and after filling it with the investigated solution. The difference in the mass of the pycnometer was divided by its volume and yielded the density value. Density determination was performed in triplicate at $37^{\circ} \mathrm{C}$.

\section{Determination of the osmotic pressure}

The osmotic pressure of the different dissolution media was determined using a vapour pressure osmometer (Wescor, Germany), calibrated with standard solutions of known osmolality.

\section{Water uptake}

Water uptake into trospium tablets was studied as a function of the viscosity of the penetrating liquid using the Enslin method. The tablet was placed on a sintered glass filter connected to a horizontal graduated capillary containing the liquid. The volume of water taken up by the tablet was measured by noting the change in the capillary reading with time. The results are reported as the mean $\pm \mathrm{SD}$ of three measurements.

\section{Disintegration}

The USP test without disks was employed to assess the media viscosity effect on the tablet disintegration rate, using a tablet disintegration tester (PharmaTest, Germany). All the tests were carried out in $800 \mathrm{ml}$ of the various media at 37 ${ }^{\circ} \mathrm{C}$ using six tablets, one per vessel, for each test. Individual disintegration times were noted and the mean $\pm S D$ reported. The disintegration study was performed in different media differing in $\mathrm{pH}$ and viscosity: SIF and acetate buffer were used as reference test media, corresponding to fasted state viscosity, whereas HPMC solutions ( $\mathrm{pH} 4.6$ and 6.8) and guar gum solutions ( $\mathrm{pH}$ 6.8) were used to simulate the fed states.

\section{Drug release}

The dissolution study of trospium tablets in simple and viscous media was performed in a rotating paddle apparatus II (PharmaTest, Germany) using $900 \mathrm{ml}$ of media at $50 \mathrm{rpm}$. All the experiments were conducted at $37^{\circ} \mathrm{C}$. Five $\mathrm{ml}$ samples were withdrawn at predetermined time intervals 5, 15, 30, 45, 60, 90 and $120 \mathrm{~min}$, filtered, properly diluted and assayed UV-photometrically (lamda 20 photometer, PerkinElmer, USA) at $210 \mathrm{~nm}$. Following analysis, dissolution versus time profiles in different media were constructed.

\section{Intrinsic dissolution}

The intrinsic dissolution was measured using the USP rotating disk method at 50 and $75 \mathrm{rpm}$ in a USP apparatus II (PharmaTest, Germany) at $37^{\circ} \mathrm{C}$. Approximately $250 \mathrm{mg}$ of pure trospium chloride was compressed under a pressure of $20 \mathrm{kN}$ force for $30 \mathrm{~s}$ using a $0.8 \mathrm{~mm}$ diameter die (Wood Apparatus, Pharma Test, Germany) into disks of $0.5 \mathrm{~cm}^{2}$ surface area for intrinsic dissolution measurements using a hydraulic press (Paul Weber, Germany). The disks were dedusted with compressed air to remove any loose particles. The dies were then placed into a holder that was immersed into the dissolution medium; the distance of the compressed drug disk from the bottom of the 
dissolution vessel was maintained at $2.5 \mathrm{~cm}$. All intrinsic dissolution measurements were performed in triplicate.

For low viscosity media, $900 \mathrm{ml}$ of dissolution medium was added to the dissolution vessel. For highly viscous media, $500 \mathrm{ml}$ of media was used in order to obtain sufficient concentrations for accurate absorbance measurement.

At appropriate time intervals $4 \mathrm{ml}$ samples were withdrawn for analysis. When $500 \mathrm{ml}$ of medium was used the dissolution medium was replaced after every sampling. Withdrawn samples were not replaced when $900 \mathrm{ml}$ medium was used. Samples were withdrawn every 2 min for low viscosity media; the time interval of sampling may reach $10 \mathrm{~min}$ for highly viscous media until seven data points had been collected.

The concentration of trospium in solution was determined as described above. The intrinsic dissolution rate (amount dissolved per unit area) was determined from the slope of the linear relationship between the amounts dissolved versus time

\section{Gastrointestinal simulation}

Gastrointestinal simulation (GastroPlus ${ }^{\circledR}$ Ver. 7.0) was used to simulate the effects of the decreased dissolution rates on plasma concentration-time profiles. Simulations were performed for a $60 \mathrm{mg}$ dose of trospium chloride. $P_{\text {eff }}$ was set to 0 for the stomach compartment and to $0.3 \times 10^{-5} \mathrm{~cm} / \mathrm{s}$ for duodenum, jejunum 1 and jejunum 2 compartments, respectively. For ileum 1 and ileum 2 a $P_{\text {eff }}$ of $0.1 \times 10^{-4} \mathrm{~cm} \mathrm{~s}^{-1}$ was set and for ileum 3 , caecum and ascending colon, a $P_{\text {eff }}$ value of 0 was set. The solubility of trospium chloride was set to $670 \mathrm{mg} / \mathrm{ml}$ and its diffusion coefficient to $0.8 \times 10^{-7} \mathrm{~cm}^{2} / \mathrm{s}$. Simulations were performed using the cumulative dissolution of trospium in SIF as input for the fasted state and in 1.4\% HPMC for the fed state, respectively. A two-compartment disposition function as described in reference [31] was used to describe the disposition parameters of trospium following i.v. dosing.

\section{Statistical analysis}

Differences between two groups were tested for significance using ANOVA with a value of $p<0.05$ as the significance level. Similarity in dissolution curves was tested by the $f_{2}$-statistic where an $f_{2}$ value between 50 and 100 suggests that two dissolution profiles are similar.

\section{Results}

\section{Determination of viscosity}

The rheological profile of the standard homogenized FDA meal revealed pseudoplastic behaviour, i.e. the viscosity decreased with an increase in the shear rate (Figure 1). Furthermore, a reduction in solution viscosity after dilution was observed. Progressive dilution of the diet reduced the viscosity from an initial $2500 \mathrm{mPa} \cdot \mathrm{s}$ to $466 \mathrm{mPa} \cdot \mathrm{s}$ at a low shear rate of $1.29 \mathrm{~s}^{-1}$ (Figure 2). These observations are in accordance with previous investigations [29]. Marciani has attributed a rapid reduction in digesta viscosity in his studies from 11000 to $2000 \mathrm{mPa} \cdot \mathrm{s}$ after the intake of a viscous meal to its gastric dilution [23].

Based on the above results, three levels of media viscosity can be defined to represent the low (15-20 mPa.s), medium (100-120 $\mathrm{mPa} \cdot \mathrm{s})$ and high (1300-1350 $\mathrm{mPa} \cdot \mathrm{s})$ viscous conditions of GI contents. Rheograms of different concentrations of HPMC (at pH 4.6 and 6.8) and guar gum solutions have been constructed. The mean viscosities of the solutions used in this study are presented in Table 2. The concentrated HPMC solutions are found to exhibit pseudoplastic flow behaviour.

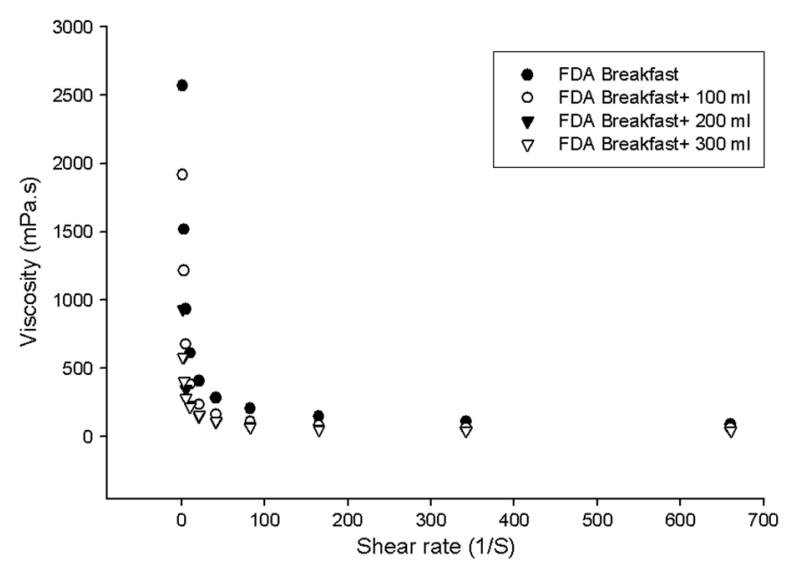

Figure 1. Viscosities of homogenized FDA meal without and with subsequent dilution with different volumes of water $(100,200,300 \mathrm{ml})$ at differing shear rates

Biopharm. Drug Dispos. 33: 403-416 (2012)

DOI: $10.1002 /$ bdd 


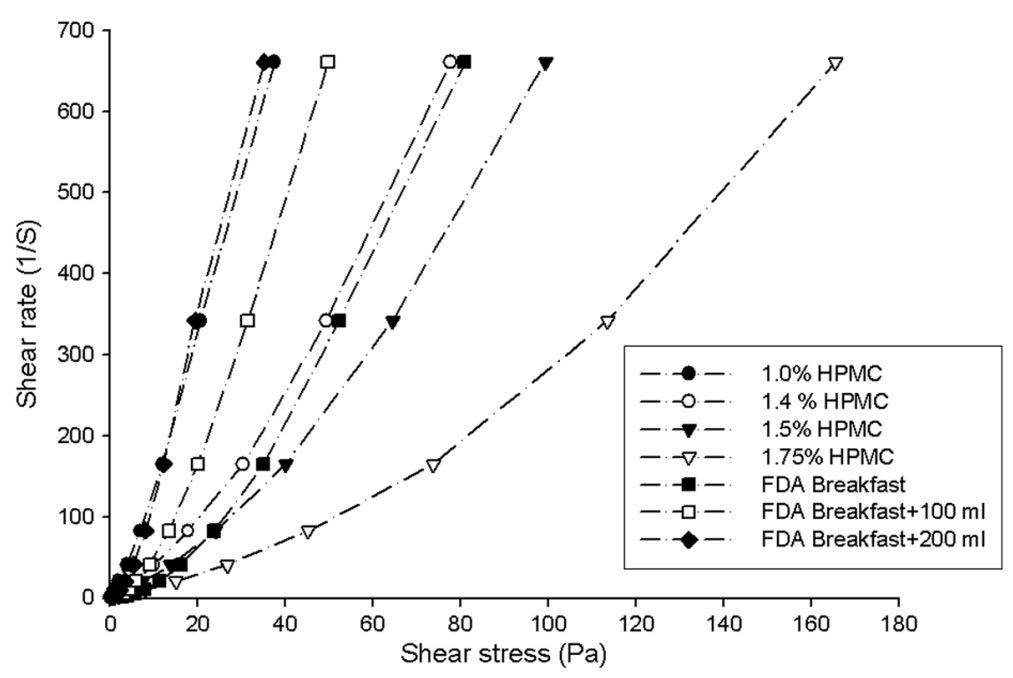

Figure 2. Rheology plots of HPMC solutions in comparison with FDA meal

The $0.5 \%$ HPMC solution showed certain deviation from the Newtonian flow at low shear rates, while at higher shear rates the flow pattern was Newtonian. There was a small reduction of the viscosity of HPMC solutions under $\mathrm{pH} 4.6$ compared with $\mathrm{pH}$ 6.8. The flow characteristics of guar gum solutions followed pseudoplastic behaviour, which is in agreement with previous studies [32].

\section{Simulation of gastric viscosity in the fed state}

By comparing the rheological profiles of different concentrations of HPMC solutions with that of the FDA standard meal, the rheogram of $1.4 \%$ (w/v) HPMC solution approximates the homogenized FDA standard meal (Figure 2). Guar gum rheograms were much inferior in simulating the viscosities of the standardized meal.

For the simulation of the dilution process, the addition of $200 \mathrm{ml}$ of the non-viscous media to $700 \mathrm{ml}$ of $1.4 \%$ HPMC viscous solution would be reasonably consistent with the dilution factor previously reported in the literature [21].

\section{Solubility and density determinations}

The results of the density and the solubility determinations of trospium chloride in the different media are presented in Table 2. Trospium solubility

Table 2. Physicochemical characteristics of trospium chloride solutions in different media. Except for solubility, determinations were performed once. For solubility, the means of $n=2-3$ and the individual values or the standard deviations are reported

\begin{tabular}{lrccr}
\hline Media & Viscosity $\eta(\mathrm{cP})$ at $1.29 \mathrm{~s}^{-1}$ & Density $(\mathrm{g} / \mathrm{ml})$ & Solubility $(\mathrm{g} / \mathrm{ml})$ & Osmotic pressure $(\mathrm{mmol} / \mathrm{kg})$ \\
\hline SIF & 1 & 0.997 & $0.786 \pm 0.021$ & 95 \\
$0.1 \mathrm{~N} \mathrm{HCl}$ & 1 & 0.991 & $0.696(0.703,0.689)$ & 188 \\
$0.5 \%$ HPMC $(\mathrm{pH}=6.8)$ & 20 & 0.993 & $0.667 \pm 0.029$ & 115 \\
$1 \%$ HPMC $(\mathrm{pH}=6.8)$ & 100 & 0.998 & $0.537(0.540,0.533)$ & 125 \\
$2 \%$ HPMC $(\mathrm{pH}=6.8)$ & 1300 & 1.004 & $0.415(0.420,0.410)$ & 200 \\
Acetate buffer & 1 & 0.990 & $0.765(0.759,0.770)$ & 74 \\
$0.5 \%$ HPMC $(\mathrm{pH}=4.6)$ & $\mathrm{ND}$ & 0.991 & $0.658(0.624,0.693)$ & 82 \\
$1 \%$ HPMC $(\mathrm{pH}=4.6)$ & $\mathrm{ND}$ & 0.994 & $0.559(0.568,0.550)$ & 84 \\
$2 \%$ HPMC $(\mathrm{pH}=4.6)$ & 900 & 0.997 & 0.79 & 105 \\
$0.25 \%$ guar $(\mathrm{pH}=6.8)$ & 15 & 0.998 & $0.787(0.770,0.803)$ & 106 \\
$0.5 \%$ guar $(\mathrm{pH}=6.8)$ & 140 & 0.998 & $0.636(0.643,0.628)$ & 109 \\
$0.75 \%$ guar $(\mathrm{pH}=6.8)$ & 1350 & 0.998 & $0.515(0.520,0.510)$ & \\
\hline
\end{tabular}

$\mathrm{ND}$, not determined. 
was high, as expected for a charged compound. Its solubility decreased in the presence of the different VEA, this may be attributed to a competition between both the hydrophilic VEA molecules and the solute molecules for the solvent. This reduction in the solubility can be considered as one of the factors influencing the dissolution process, albeit its effect is probably limited. There was no apparent effect of $\mathrm{pH}$ on trospium solubility in viscous HPMC media when comparing results at $\mathrm{pH} 4.6$ and 6.8 , respectively.

\section{Effect of osmotic pressure}

The osmotic pressure of the different dissolution media is depicted in Table 2. Only small differences in the osmotic pressure with concentration of VEAs were observed in HPMC and guar solutions, probably since their molecular weight is high.

\section{Water uptake}

Since water uptake is the preliminary step in the disintegration mechanism, its characterization is important towards a better understanding of drug release. A linear relationship between water uptake and time was observed (data not shown). The water uptake rate was calculated from the slope of the plot. The results are shown in Table 3.

It can be seen that water uptake into the different tablets was reduced by the addition of the VEA, and was accompanied by prolonged lag times. A significant reduction in the water uptake rate appeared by increasing the concentration of the polymer. Furthermore, differences in lag times can be observed. Longer lag times are reported for coated tablets (Spasmex ${ }^{\circledR}$ and Spasmolyt ${ }^{\circledR}$ ) compared with the uncoated tablet $\left(\operatorname{Trospi}^{\circledR}\right)$.

\section{Disintegration study}

The average disintegration times are shown in Figure 3. The results clearly demonstrate the potential for media viscosity to significantly delay tablet disintegration. In non-viscous media, all investigated products exhibited fast disintegration. The disintegration times under viscous conditions were significantly prolonged for the three formulations $(p<0.05)$. Disintegration times in 1.4\% HPMC were increased from an average value of $3.5 \mathrm{~min}$ in SIF to 18, 22 and 35 min for Trospi ${ }^{\circledR}$, Spasmex ${ }^{\circledR}$ and Spasmolyt ${ }^{\circledR}$, respectively. The change of $\mathrm{pH}$ at identical concentrations of VEA did not significantly affect disintegration times.

Differences in the behaviour of the three formulations in the different media were obvious (Figure 4).

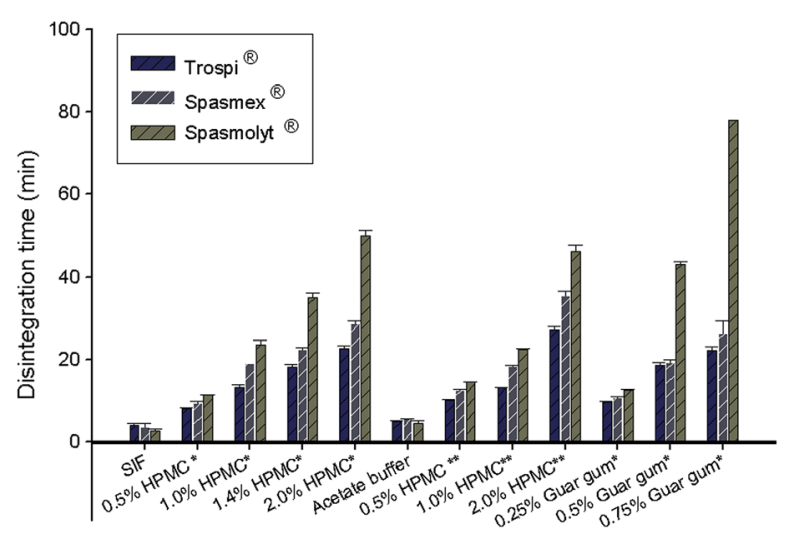

Figure 3. Disintegration times of various trospium chloride products in different disintegration media. The effects of increasing media viscosity on disintegration times were in all cases significant $(p<0.05)$, whereas the effect of change of $\mathrm{pH}$ for HPMC solutions at the same concentrations of VEA was insignificant $(p>0.05) .{ }^{*} \mathrm{pH} 6.8 ;{ }^{* *} \mathrm{pH} 4.6$

Table 3. Water uptake rates and lag times by tablets (mean $\pm \mathrm{SD}, n=3-5$ )

\begin{tabular}{|c|c|c|c|c|c|c|}
\hline \multirow[t]{2}{*}{ Media } & \multicolumn{2}{|c|}{ Spasmolyt } & \multicolumn{2}{|c|}{ Spasmex } & \multicolumn{2}{|l|}{ Trospi } \\
\hline & Rate ${ }^{*} 10^{-3}(\mathrm{ml} / \mathrm{min})$ & $T$ lag (min) & $\operatorname{Rate}^{*} 10^{-3}(\mathrm{ml} / \mathrm{min})$ & $T$ lag (min) & Rate $^{*} 10^{-3}(\mathrm{ml} / \mathrm{min})$ & $T$ lag (min) \\
\hline SIF & $8.0 \pm 1.05$ & $1.0 \pm 0$ & $6.4 \pm 0.01$ & $1.0 \pm 0.1$ & $8.5 \pm 0.48$ & $0.8 \pm 0.28$ \\
\hline $0.5 \% \mathrm{HPMC}$ & $1.9 \pm 0.08$ & $12.0 \pm 6.5$ & $3.4 \pm 0.17$ & $14.0 \pm 3.6$ & $3.3 \pm 0.06$ & $5.3 \pm 1.15$ \\
\hline $1 \% \mathrm{HPMC}$ & $0.5 \pm 0.01$ & $16.0 \pm 6.9$ & $0.7 \pm 0.08$ & $17.0 \pm 1.4$ & $0.7 \pm 0.07$ & $14.8 \pm 3.70$ \\
\hline $2 \%$ HPMC & $0.3 \pm 0.10$ & $28.0 \pm 1.4$ & $0.4 \pm 0.01$ & $25.0 \pm 2.1$ & $0.4 \pm 0.02$ & $22.0 \pm 2.12$ \\
\hline $0.25 \%$ guar & $6.5 \pm 0.30$ & $3.5 \pm 0.7$ & $6.3 \pm 0.39$ & $11.5 \pm 6.4$ & $5.1 \pm 0.40$ & $1.8 \pm 1.04$ \\
\hline $0.5 \%$ guar & $1.0 \pm 0.10$ & $13.3 \pm 0.6$ & $1.6 \pm 0.10$ & $14.3 \pm 3.2$ & $1.2 \pm 0.07$ & $6.3 \pm 2.08$ \\
\hline $0.75 \%$ guar & $0.5 \pm 0.05$ & $42 \pm 16.0$ & $0.5 \pm 0.02$ & $23 \pm 1.4$ & $0.4 \pm 0.01$ & $10.5 \pm 2.12$ \\
\hline
\end{tabular}




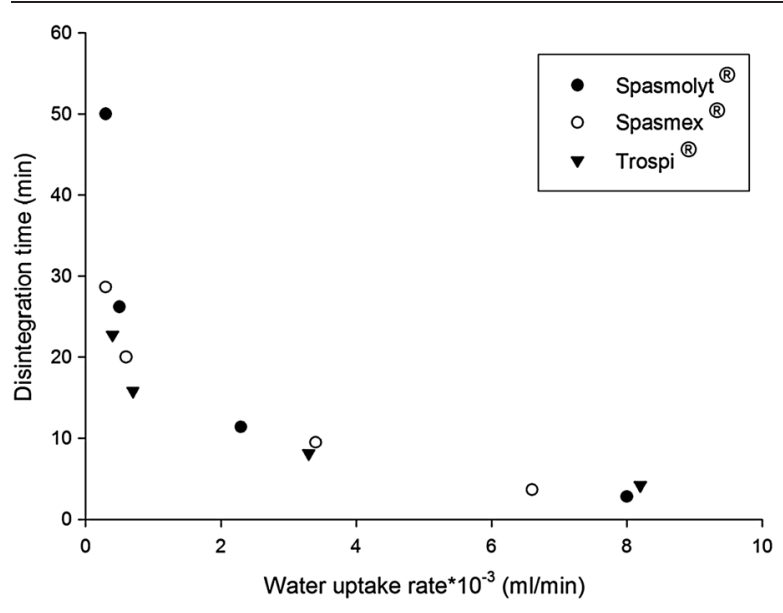

Figure 4. Relationship between water uptake into tablets and tablet disintegration times

The uncoated tablet $\left(\operatorname{Trospi}{ }^{\circledR}\right)$ was least affected by an increase in the viscosity of the media. Film coated tablets, on the other hand, showed comparatively longer disintegration times. Furthermore, it was noted that both film-coated tablets did not behave in a similar manner. For Spasmolyt ${ }^{\circledR}$ relatively longer disintegration times in viscous media were measured compared with Spasmex ${ }^{\circledR}$. There was a good, although nonlinear, correlation between water uptake into the tablets and disintegration rates (Figure 4), an observation that confirms the results reported by Anwar et al. [9] who reported a good correlation between the liquid penetration rate into the tablet and the resulting disintegration times. The increase in media viscosity after food ingestion is not the only explanation for delayed disintegration of trospium chloride tablets; film formation around the tablet was suggested by Abrahmsson as another explanation [11].

\section{Dissolution study}

The in vitro dissolution of the different trospium formulations was investigated in the different media. Figure 5a-c illustrates the dissolution profiles for the three products in the presence and absence of the different VEAs at various concentrations.

The rates of drug release under simulated fasting conditions were faster compared with simulated fed conditions. Under simulated fasting conditions, the different products containing trospium chloride were completely dissolved within $15 \mathrm{~min}$, reflecting the very rapid tablet disintegration and the high solubility of the drug substance. A viscosity increase in the media resulted in a decrease in the dissolution of trospium from the different formulations in a concentration dependent manner. F2 similarity factors were generally less than 50, indicating significant differences in the dissolution profiles at various viscosities. Drug release from the different formulations in 1.4\% HPMC, which has a viscosity similar to the FDA standard meal, was reduced to less than 50\%. In 2\% HPMC solutions, dissolution was very slow, i.e. less than $20 \%$ of the drug was dissolved within $120 \mathrm{~min}$. These findings are in agreement with the result previously obtained by Parojcic et al. who observed a delay in the dissolution and disintegration rates of paracetamol tablets in viscous media [9]. In guar gum enhanced viscous media, similar findings, though not identical, were observed. Equiviscous solutions of different VEAs thus resulted in different dissolution patterns. At high viscosities, the dissolution profiles in HPMC appeared to be reduced compared with those in equiviscous solutions of guar gum.

Reducing the $\mathrm{pH}$ of the dissolution media was found to exert no effect on the drug release patterns from the investigated tablets at HPMC concentrations above 1\% (similarity factors $>50$ ). However, at lower HPMC concentrations, changing the $\mathrm{pH}$ showed significant effects on the dissolution process. Figure $6 \mathrm{a}-\mathrm{c}$ illustrates the $\mathrm{pH}$ effect on drug release profiles for the three tablets in the viscous HPMC solutions. In SIF media $\mathrm{pH}$ 6.8, complete drug release was observed within $15 \mathrm{~min}$, whereas, at a lower $\mathrm{pH}$ acetate buffer 4.6 , the total percentage of drug release was reduced to $86 \%$.

In general, good correlations were obtained between disintegration times and dissolution rates in viscous media (Figure 7). It is evident that the lower dissolution rates observed in viscous media reflect the prolonged disintegration and the reduced liquid penetration rates.

\section{Intrinsic dissolution}

The results from the intrinsic dissolution experiments are shown in Table 4. The IDR of the drug was found to be affected by the viscosity of the media. The intrinsic dissolution rate is inversely proportional to the viscosity of the medium. Thus 

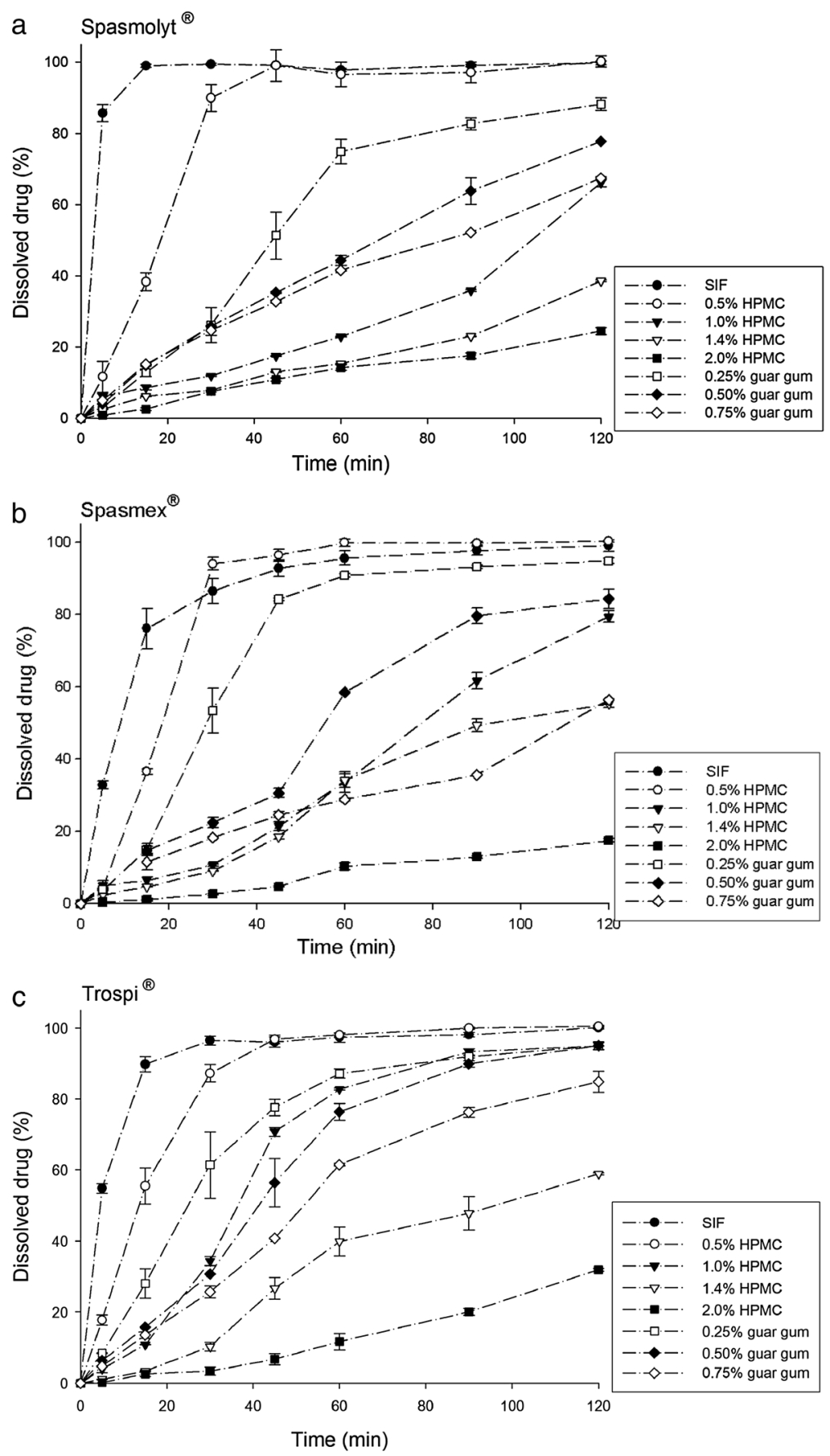

Figure 5. (a) Dissolution profiles for Spasmolyt ${ }^{\circledR}$ in viscous HPMC and guar solutions at pH 6.8, 50 rpm in USP-2 apparatus. In all cases values for $f_{2}$ were $<50$. Mean $\pm S D, n=3$. (b) Dissolution profiles for Spasmex ${ }^{\circledR}$ in viscous HPMC and guar solutions at $\mathrm{pH}$ $6.8,50 \mathrm{rpm}$ in USP-2 apparatus. In all cases values for $f_{2}$ were $<50$. Mean $\pm \mathrm{SD}, n=3$. (c) Dissolution profiles for Trospi ${ }^{\circledR}$ in viscous HPMC and guar solution at $\mathrm{pH} 6.8,50 \mathrm{rpm}$ in USP-2 apparatus. In all cases values for $f_{2}$ were $<50$. Mean $\pm \mathrm{SD}, n=3$ 

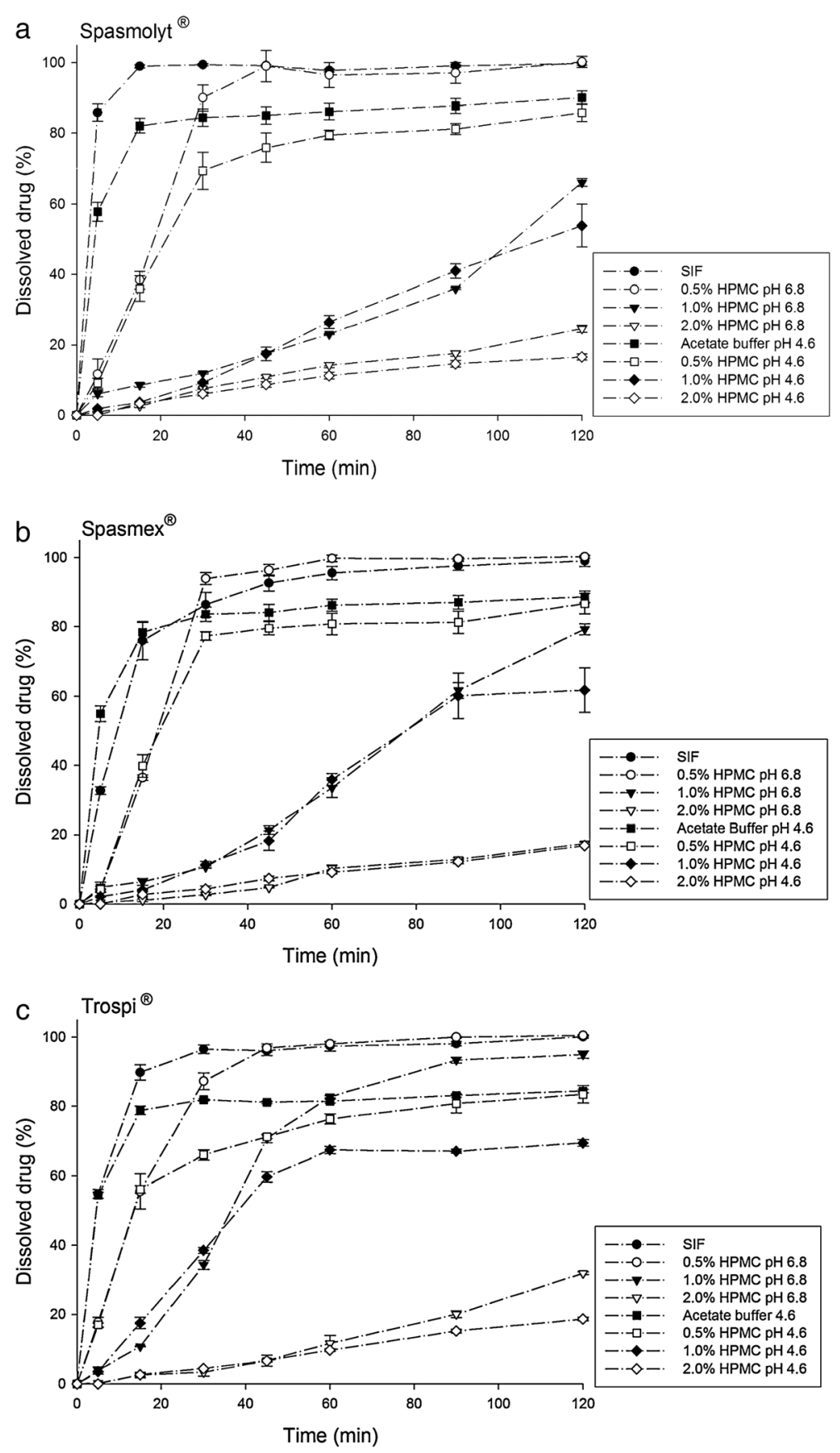

Figure 6. (a) Effect of $\mathrm{pH}$ on dissolution of trospium from Spasmolyt ${ }^{\circledR}$ tablets in solutions with differing viscosities. Only at concentrations of HPMC $<1.0 \% f_{2}$ factors were $<50$. Mean $\pm S D, n=3$. (b) Effect of $\mathrm{pH}$ on dissolution of trospium from Spasmex ${ }^{\circledR}$ tablets in solutions with differing viscosities. Only at concentrations of $\mathrm{HPMC}<1.0 \% f_{2}$ factors were $<50$. Mean $\pm \mathrm{SD}, n=3$. (c) Effect of $\mathrm{pH}$ on dissolution of trospium from Trospi ${ }^{\circledR}$ tablets in solutions with differing viscosities. Only at concentrations of $2 \%$ HPMC the $f_{2}$ factor was equal to 63 . Mean $\pm \mathrm{SD}, n=3$ 


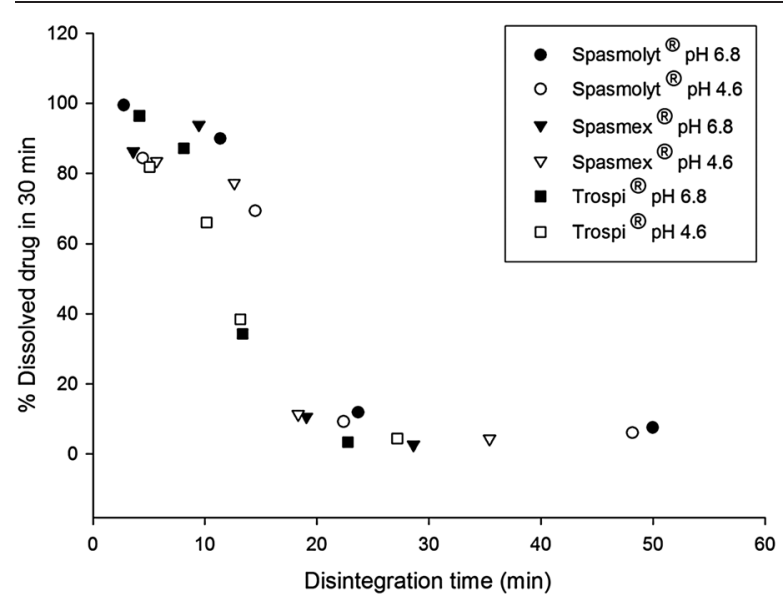

Figure 7. Relationship between dissolution and disintegration times for various products of trospium chloride

the addition of HPMC at a low concentration reduces the dissolution rate. A similar trend is observed in the guar gum solution. The IDR is found to increase with increasing agitation intensity from $50 \mathrm{rpm}$ to $75 \mathrm{rpm}$. This can be attributed to the decreased diffusion layer thickness resulting in increased mass transport from the matrix surface.

Gastrointestinal simulation of the effect of decrease in dissolution rate on plasma concentration versus time profiles and fraction absorbed

The results of the gastrointestinal simulation are shown in Figure 8. The model described the experimental plasma concentration-time profile quite well in the fasted state and it also predicts a severe decrease in the fed state. However, the decrease in

Table 4. Intrinsic dissolution rates for trospium chloride at different agitation rates (mean $\pm \mathrm{SD}, n=3$ )

\begin{tabular}{lcr}
\hline Media & $\begin{array}{c}R_{\text {exp75rpm }} \\
\left(\mathrm{mg} / \mathrm{cm}^{2} \mathrm{~min}\right)\end{array}$ & $\begin{array}{r}R \text { exp50 } \mathrm{rpm} \\
\left(\mathrm{mg} / \mathrm{cm}^{2} \mathrm{~min}\right)\end{array}$ \\
\hline SIF & $17.5 \pm 0.81$ & $15.5 \pm 0.60$ \\
$0.1 \mathrm{~N} \mathrm{HCl}$ & $17.7 \pm 0.35$ & $15.3 \pm 0.70$ \\
$0.5 \% \mathrm{HPMC}$ & $14.2 \pm 0.44$ & $10.2 \pm 1.06$ \\
1.0\% HPMC & $9.4 \pm 0.75$ & $6.5 \pm 0.30$ \\
2.0\% HPMC & $3.9 \pm 0.04$ & $2.2 \pm 0.17$ \\
$0.25 \%$ guar gum & $17.9 \pm 0.97$ & $13.6 \pm 0.46$ \\
$0.5 \%$ guar gum & $11.8 \pm 1.25$ & $5.9 \pm 0.68$ \\
$0.75 \%$ guar gum & $4.8 \pm 0.16$ & $1.0 \pm 0.13$ \\
\hline
\end{tabular}

Copyright (C) 2012 John Wiley \& Sons, Ltd.

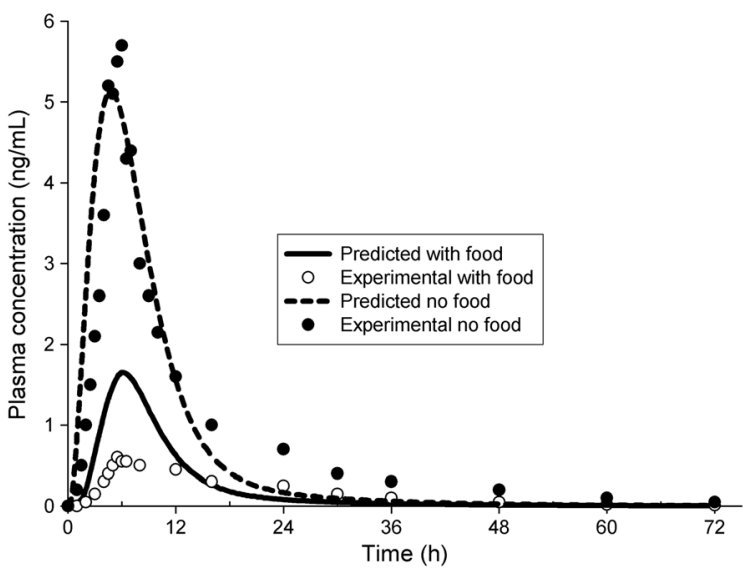

Figure 8. Simulated and predicted plasma concentration-time profiles for trospium in fasted and fed states in humans

plasma concentrations in the presence of food was somewhat underestimated. For example, the predicted $C_{\max }$ was $1.7 \mathrm{ng} / \mathrm{ml}$ by the model, whereas the average measured $C_{\max }$ was only 0.6 $\mathrm{ng} / \mathrm{ml}$. This demonstrates that additional factors of unknown mechanism may contribute to the negative food effect of trospium and need to be investigated further.

\section{Discussion}

It is evident that increasing the media viscosity had a profound influence on drug disintegration and dissolution. This effect was found to be mediated mainly through the water penetration process.

Water uptake is the initial step in the disintegration process, thus factors affecting liquid penetration into the tablet will affect its disintegration rate. The Washburn equation can be used to describe the critical parameters influencing liquid penetration into the tablet [33]. According to this equation, liquid uptake into non-disintegrating porous tablets is adversely affected by the viscosity of the penetrating liquid. Although the equation is of limited applicability here, since the tablet is disintegrating and porosity is changing with time, an inverse relation between liquid viscosity and its penetration rate into tablets is suggested, which may explain the reduced water uptake by tablets in highly viscous media. 
These findings suggest an impact of gastric viscosity on drug release and bioavailability. Media having viscosity similar to that of the FDA standard meal showed reduced dissolution and disintegration rates.

The differences observed in the disintegration and dissolution behaviour between equiviscous HPMC and guar gum polymeric solutions can be related to the chemical structure of the polymer chain. Guar gum is a branched polymer with compact structure, whereas HPMC chains are linear structures offering more resistance to drug and water diffusivity.

$C^{*}$ (coil overlap concentration) is a characteristic concentration for each polymer, above which the coils of the polymer chains begin to overlap and entangle with one another leading to an abrupt increase in viscosity and decrease in solute diffusivity. Drug dissolution can be significantly decreased at concentrations above $C^{*}$ through reduced diffusivity [34]. The $C^{*}$ for HPMC has been determined previously to be $0.57 \%$ [35] This may help to explain the significant difference in drug dissolution between $0.5 \%$ and $1 \%$ HPMC solutions. The $C^{*}$ value for guar gum was found to be $0.2 \%$ [34]. The concentrations of guar gum used in this study were beyond this value. Reduced diffusivity in viscous media could explain the low liquid penetration rates and the subsequent prolonged disintegration times and reduced dissolution profiles.

There is a good correlation between water penetration rate into tablet, disintegration time and dissolution rate in different viscous media. The SIF medium showed the fastest penetration rates and exhibited the shortest disintegration times. Polymeric solutions exhibit slower rates of fluid penetration into tablets, and slower disintegration. The prolonged disintegration times may be responsible for the reduced dissolution profiles observed in viscous media.

The overall effect was more pronounced for film coated tablets, which could be explained by the swelling of the HPMC coat layer surrounding the tablet, acting as a barrier for the diffusion of the solvent and drug molecules in and out of the tablet and offering a longer diffusional path length. Differences between coated and uncoated tablets can be observed, that may be attributed to the variation in the coating thickness and excipients included that were not obvious by using SIF as media for disintegration or dissolution. These findings are supported by previous reports. Galia reported the slow dissolution of film coated pandol tablets in milk compared with non-coated acetaminophen tablets, which was as attributed to a chemical interaction between milk and tablet excipients [28].

In the present study, the role of viscosity on the drug release process has been assessed. It is evident that food viscosity can delay drug dissolution and tablet disintegration. This is of particular importance for solid dosage forms containing BCS class III compounds that may undergo preferential absorption in the upper small intestine. A delay in drug release will supply the dissolved drug distal to the absorption site, thus reducing the fraction of absorbed drug and sometimes the therapeutic efficacy.

Media viscosity should be considered for adequate prediction of food effect on drug release. Previous models were not physiologically relevant to the actual fed state from the viscosity point of view. In this study $1.4 \%$ HPMC solutions are suggested for the simulation of the postprandial conditions of the GI tract but further work is needed for establishing in vitro/in vivo correlation.

\section{Conclusion}

The results suggest that food viscosity plays an important role in the dissolution process of BCS class III drugs. Changes in disintegration times may be responsible for the different dissolution profiles observed in these different media. Changes in media viscosity can significantly influence the disintegration times of tablets through changes in liquid penetration rates.

Various media have been proposed for simulation of the fed state; however, these media did not reflect the viscosity conditions within the GI tract. In the present study, the addition of a viscosity enhancing agent for more accurate simulation of the fed conditions is suggested. Viscosity is shown to be an important factor affecting dissolution and disintegration of dosage forms - thus when defining a dissolution medium to simulate the postprandial state, viscosity should be considered as a relevant factor. 


\section{Acknowledgements}

This research was supported by grants from the German Academic Exchange Service (DAAD) to A.R. and the Humboldt Foundation to G.L.A.

\section{Conflict of Interest}

The authors report no conflict of interest.

\section{References}

1. Levy G, Jusko WJ. Effect of viscosity on drug absorption. J Pharm Sci 1965; 54: 219-225.

2. Jaffe JM, Colaizzi JL, Barry H. Effects of dietary components on GI absorption of acetaminophen tablets in man. J Pharm Sci 1971; 60: 1646-1650.

3. Soci MM, Parrott EL. Influence of viscosity on absorption from nitrofurantoin suspensions. $J$ Pharm Sci 1980; 69: 403-406.

4. Eshra AG, Etman MA, Naggar VF. Effect of milk and food on the bioavailability of ketoprofen in man. Int J Pharm 1988; 44: 9-14.

5. Fleisher D, Li C, Zhou Y, Pao LH, Karim A. Drug, meal and formulation interactions influencing drug absorption after oral administration, clinical implications. Clin Pharmacokinet 1999; 36: 233-254.

6. Reppas C, Eleftheriou G, Macheras P, Symillides $M$, Dressman JB. Effect of elevated viscosity in the upper gastrointestinal tract on drug absorption in dogs. Eur J Pharm Sci. 1998; 6: 131-139.

7. Ehrlein HJ, Pröve J. Effect of viscosity of test meals on gastric emptying in dogs. Q J Exp Physiol 1982; 67: 419-425.

8. Anwar S, Fell JT, Dickinson PA. An investigation of the disintegration of tablets in biorelevant media. Int J Pharm 2005; 290: 121-127.

9. Parojčić J, Vasiljević D, Ibrić S, Djurić Z. Tablet disintegration and drug dissolution in viscous media: paracetamol IR tablets. Int J Pharm 2008; 355: 93-99.

10. Kalantzi L, Polentarutti B, Albery T, et al. The delayed dissolution of paracetamol products in the canine fed stomach can be predicted in vitro but it does not affect the onset of plasma levels. Int J Pharm 2005; 296: 87-93.

11. Abrahamsson B, Albery T, Eriksson A, Gustafsson I, Sjoberg M. Food effects on tablet disintegration. Eur J Pharm Sci 2004; 22: 165-172.

12. Sarisuta N, Parrott EL. Relationship of dissolution rate to viscosity of polymeric solutions. J Pharm Sci 1982; 71: 1375-1380.
13. Braun RJ, Parrott EL. Influence of viscosity and solubilization on dissolution rate. J Pharm Sci 1972; 61: 175-178.

14. Chang SH, Parrott EL. Relationship of dissolution rate in anionic polymeric solutions to viscosity. Drug Dev Ind Pharm 1991; 17: 201-213.

15. Smidt JH, Offringa JCA, Crommelin DJA. Dissolution kinetics of theophylline in aqueous polymer solutions. Int J Pharm 1991; 77: 255-259.

16. Khoury N, Mauger JW, Howard S. Dissolution kinetics of hydrocortisone into dilute polymer solutions. Drug Dev Ind Pharm 1991; 17: 349-371.

17. Blackburn NA, Johnson IT. The effect of guar gum on the viscosity of the gastrointestinal contents and on glucose uptake from the perfused jejunum in the rat. Br J Nutr 1981; 46: 239-246.

18. Roberts FG, Smith HA, Low AG, Ellis PR, Morris ER, Sambrook IE. Influence of guar gum flour of different molecular weights on viscosity of jejunal digesta in the pig. Proc Nutr Soc 1990; 49: 53A.

19. Reppas C, Meyer JH, Sirois PJ, Dressman JB. Effect of hydroxypropylmethylcellulose on gastrointestinal transit and luminal viscosity in dogs. Gastroenterology 1991; 100: 1217-1223.

20. Dikeman CL, Murphy MR, Fahey GC Jr. Dietary fibers affect viscosity of solutions and simulated human gastric and small intestinal digesta. J Nutr 2006; 136: 913-919.

21. Marciani L, Gowland PA, Spiller RC, et al. Effect of meal viscosity and nutrients on satiety, intragastric dilution, and emptying assessed by MRI. Am J Physiol Gastrointest Liver Physiol 2001; 280: G1227-G1233.

22. Gallaher DD, Wood KJ, Gallaher CM, Marquart LF, Engstrom AM. Intestinal contents supernatant viscosity of rats fed oat-based muffins and cereal products. Cereal Chem 1999; 76: 21-24.

23. Marciani L, Gowland PA, Spiller RC, et al. Gastric response to increased meal viscosity assessed by echo-planar magnetic resonance imaging in humans. J Nutr 2000; 130: 122-127.

24. $\mathrm{Gu} \mathrm{CH}, \mathrm{Li} \mathrm{H}$, Levons J, et al. Predicting effect of food on extent of drug absorption based on physicochemical properties. Pharm Res 2007; 24: 1118-1130.

25. Doroshyenko O, Jetter A, Odenthal KP, Fuhr U. Clinical pharmacokinetics of trospium chloride. Clin Pharmacokinet 2005; 44: 701-720.

26. Hotha KK, Bharathi DV, Kumar SS, et al. Determination of the quaternary ammonium compound trospium in human plasma by LC-MS/MS: application to a pharmacokinetic study. J Chromatogr B 2010; 13-14: 981-986.

27. Jantratid E, Janssen N, Reppas C, Dressman JB. Dissolution media simulating conditions in the proximal human gastrointestinal tract: an update. Pharm Res 2008; 25: 1663-1676.

28. Galia E, Nicolaides E, Hörter D, Löbenberg R, Reppas C, Dressman JB. Evaluation of various 
dissolution media for predicting in vivo performance of class I and II drugs. Pharm Res 1998; 15: 698-705.

29. Klein S, Butler J, Hempenstall JM, Reppas C, Dressman J. Media to simulate the postprandial stomach I: Matching the physicochemical characteristics of standard breakfasts. J Pharm Pharmacol 2004; 56: 605-610.

30. FDA. Guidance for Industry: Food Effect Bioavailability and Fed Bioequivalence Studies. US Department of Health and Human Services, Food and Drug Administration, Center for Drug Evaluation and Research, (CDER): Rockville MD, USA, 2002.

31. Schladitz-Keil G, Spahn H, Mutschler E. Determination of the bioavailability of the quaternary compound trospium chloride in man from urinary excretion data. Drug Res 1986; 36: 984-987.

32. Patel SP, Ranjan G, Patel VS. Rheological properties of guar gum and hydroxyethyl guar gum in aqueous solution. Int $J$ Biol Macromol 1987; 99: 314-320.

33. Washburn EW. The dynamics of capillary flow. Phys Rev 1921; 17: 273-283.

34. Baines ZV, Morris ER. Flavour/taste perception in thickened systems: the effect of guar gum above and below C*. Food Hydrocoll 1987; 3: 197-205.

35. Cook DJ, Hollowood TA, Linforth RST, Taylor AJ. Perception of taste intensity in solutions of random-coil polysaccharides above and below $\mathrm{C}^{*}$. Food Qual Prefer 2002; 13: 473-480. 